Military Technical College

Kobry Elkobbah, Cairo, Egypt

May 27-29,2008

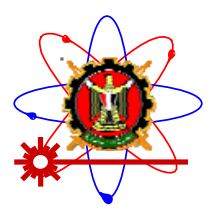

$4^{\text {th }}$ International Conference on Mathematics and Engineering Physics (ICMEP-4)

PH-12

\title{
Ameliorative Effects of He:Ne Laser Irradiation on DNA Damage of Blood of Children with Acyanotic Heart Disease
}

\author{
Ekram Abdel Salam*, Rabha El Shinawy*, Soheir Korraa**, Iman E. Abdel Meguid* and \\ Gihan El Sharnouby***
}

\begin{abstract}
Low-energy laser irradiation (LELI) has been found to attenuate various biological processes in tissue culture and experimental animal models. The aim of the present study was to investigate the role of LELI in ameliorating markers of oxidative stress (in terms of blood antioxidant enzymes levels, NO generation, apoptotic genes together with DNA fragmentation and apoptosis percentage in circulating lymphocytes) in cyanotic and acyanotic congenital heart diseases with reference to normal healthy children. Accordingly, whole blood from 16 cyanotic, 14 acyanotic and 15 controls was exposed to $8 \mathrm{~mW} \mathrm{He}-\mathrm{Ne}$ laser at energy densities of $3 \mathrm{~J} / \mathrm{cm}^{2}$ and examined before, after and without laser exposure 24 hours post irradiation for levels blood antioxidant enzymes, NO generation, Bax RNA and Bcl2 protein together with DNA fragmentation and apoptosis percentage in circulating lymphocytes. Results indicated that there were significant increases in mean $\pm \mathrm{SD}$ of plasma nitrite, MDA, DNA fragmentation and apoptosis in circulating lymphocytes of both acyanotic and cyanotic cases compared to controls before laser irradiation. Laser ameliorated oxidative stress in acyanotic heart disease blood, but increased apoptosis and DNA fragmentation in cyanotic cases 24 hours post laser irradiation. In control cases laser had a biostimulatory effect exhibited by decreased lipid peroxidation, apoptosis and DNA fragmentation compared to its level without laser irradiatioin. Also, there was significant increase in plasma nitrite in controls, cyanotic and acyanotic cases 24 hours post irradiation with laser compared to their level without laser irradiation. However, cyanotic cases showed the highest significant value and were significantly higher when compared to both cyanotic and acyanotic cases. It is concluded that $\mathrm{He}: \mathrm{Ne}$ laser have an ameliorative effect on damaging effects induced due cardiac catheterization procedure in case of acyanotic congenital heart diseases, but it worsen the effects in cyanotic congenital heart diseases. Increased nitric oxide production seems to be the reason for the increased oxidative stress in cyanotic heart diseases, which are worsened when exposed to laser irradiation.
\end{abstract}

\section{Introduction:}

Lately there has been an argument about for feasibility of laser beam usage in ischemic heart disease treatments. Photo-irradiation causes a variety of effects in different cells and tissues, such as facilitating wound healing (1) and promoting the process of regeneration and angiogenesis (2-4) Current laboratory and experimental studies have indicated that lowenergy laser radiation both exerts both antiischemic and $(5,6)$ anti-inflammatory effects $(7$, 8). Recent studies showed that argon dye laser (660-nm wavelength) improves the functional 
recovery of cold-stored, isolated rat cardiomyocytes (9) and that that epicardial low level laser irradiation of rat and dog hearts after chronic myocardial infarcture caused a marked reduction in infarct size, probably due to a cardioprotective effect of the LELI (10).

Congenital heart disease (CHD) represents 3-4 \% of all cardiac defects; 4/10,000 live births (11). In both acyanotic and cyanotic congenital heart disease, oxygen delivery is impaired either by reduced pulmonary perfusion or by limited entry of oxygenated blood into the systemic circulation leading to hypoximia (12). Hypoxia alters almost every aspect of cellular physiology, since mammalian cells exhibit many adaptive responses to hypoxia. Recent work has implicated that mitochondria generate reactive oxygen species (ROS) in response to hypoxia. ROS are known to participate in other transcriptional responses (13), including the transcriptional activation of erythropoietin (EPO) (14), apoptosis (15), glycolytic enzymes (16) antioxidant enzymes (17) and inducible nitric oxide synthase enzyme (18). Systemically, these responses enhance the delivery of $\mathrm{O}_{2}$ to cells and facilitate the production of glycolytic ATP. Thus hypoxia is a potential cause for the generation of reactive oxygen species $(19,20)$. The ROS that might be formed include superoxide, hydrogen peroxide, nitric oxide, and hydroxyl radicals. ROS are reactive chemical species that differ from other compounds in that they have unpaired electrons in their outermost orbital. They are highly reactive molecules that avidly attack biomolecules (21) including cellular DNA, proteins and lipids inducing DNA-damage (22), protein carbonyls and lipid peroxidation (23).

Since He:Ne laser has been shown to exhibit antioxidant properties (24). This study was designed in vitro to investigate, whether low intensity laser irradiation exhibits ameliorative effects on oxidative damage induced due to hypoxia on blood components of both cyanotic and acyanotic children with congenital heart diseases. The parameters of biological markers of oxidative stress investigated in this study were apoptosis percentage and DNA fragmentation in circulating lymphocytes, blood levels of NO, apoptotic genes (Bax and $\mathrm{Bcl} 2$ ) together with antioxidant enzymes levels.

\section{Patients and Methods}

\section{Patients}

30 child with congenital heart disease at the pediatric department, Cairo University. They were 16 males and 14 females (age range $1.5-5$, mean age $3 \pm 1.8 .2$ years) compared to 15 age and sex matching healthy normal children as a control group (age range 1.5 - 5). Blood was drawn after an informed consent of the parents in accordance with the current revision of the 1975 Helsinki Declaration and was approved by the ethical committees of the hospitals.. The patients and were further classified as cyanotic and acyanotic and were subjected to full history taking ,clinical examination, and routine investigation as x-ray, ECG, ECHO and CBC.

\section{Methods}

\section{Blood Irradiation:}

Blood was drawn before and immediately after the termination of cardiac catheterization procedure. Blood obtained before catheterization was assayed directly. Parts of blood obtained after catheterization were distributed over 96 well tissue culture plates and were incubated for 24 hours with and without irradiation with $2 \mathrm{~J} / \mathrm{cm}^{2} \mathrm{He}: \mathrm{Ne}$ laser at wave length $632.8 \mathrm{~nm}$. Part of control's blood was assayed directly and other parts were distributed over 96 well tissue culture plates and were incubated for 24 hours with and without irradiation with $2 \mathrm{~J} / \mathrm{cm}^{2} \mathrm{He}: \mathrm{Ne}$ laser at wave length $632.8 \mathrm{~nm}$.

\section{Laboratory Methods}




\section{Determination of Blood Antioxidant Enzymes:-}

Antioxidant enzyme activities were assayed in whole blood samples. GPx activity was measured by RANSEL glutatione peroxidase kit (25), where the Units of enzyme activity were calculated using the millimolar asorptivity for NADPH. SOD was assayed using the RASOD superoxide dismutase kit which incorporates xanthine oxidase to generate $\mathrm{O}_{2}{ }^{-2}(26)$. CAT peroxidative activity was measured by the reaction of formaldehyde produced from methanol with Purpald to produce a chromophore, whose absorbance is measured at $540 \mathrm{~nm}$ (27).

\section{Apoptosis in Circulating Lymphocytes}

Ficol separated lymphocytes were subjected to a double staining technique (28). They were washed and briefly incubated with fluoreceine diacetate for 15 minutes rewashed and fixed with 70\% Ethyl alchol incubated with RNAase for 15 minutes and then stained with and propdium iodide. Viable cells will take up fluoresciene diacetate and fluoresce in green, while dead cells will allow propidium iodide to traverse the cell membrane stain with nuclear DNA giving and red fluorescence. RNA present in an apoptotic cells will be removed by RNA-ase to eliminate confusion with nuclear DNA.

\section{ELISA Bcl 2 :}

The amounts of $\mathrm{Bcl}_{2}$ were determined by a sandwich enzyme linked immunosorbent assay (ELISA) using two anti-human BCL2 monoclonal murine antibodies (29). The measurement was as follows: A 96 well plate coated with anti-human $\mathrm{Bcl}_{2}$ antibody $(10 \mu \mathrm{g} / \mathrm{ml}$ diluted with phosphate buffer saline, PBS) overnight at $4^{\circ} \mathrm{C}$. After washing the plate with PBS containing $0.05 \%$ Tween 20 (T-PBS), the wells were blocked by skimmed milk solution for 2 hours at $37^{\circ} \mathrm{C}$. lysed lymphocytes were diluted twice with $1 \%$ bovine serum albumin (BSA)/PBS. Fifty $\mu 1$ of the samples and standard $\mathrm{Bcl}_{2}$ (diluted with $1 \% \mathrm{BSA} / \mathrm{PBS}$ ) were added to the well and incubated for 1 hour at room temperature. After washing with T-PBS, biotinylated NOK1 anti-human FasL antibody (5 $\mu \mathrm{g} / \mathrm{ml}$ containing 5\% mouse serum) was added and incubated for 1 hour at room temperature. The wells were washed five times with T-PBS and incubated with $50 \mu \mathrm{l}$ tetramethyl benzidin (MO, USA) for 1 hour at room temperature. Chromegen activity was detected by absorbance measured at $450 \mathrm{~nm}$ using an ELISA reader

\section{Nitrite/nitrate in plasma}

Nitrate in the sample was reduced to nitrite by nitrate reductase prepared from Escherichia coli (Sigma) in $20 \mathrm{mM}$ Tris- $\mathrm{HCl}$ buffer containing $40 \mu \mathrm{M}$ NADPH (Sigma Chemicals, St Louis, MO, USA) as described previously Misko et al. (30). The Griess reagents were used to determine the nitrite concentration (31). Sodium nitrate was also used as the standard to ensure the efficacy of the nitrate reductase. These reactions were performed in a 96-well microplate and optical density at $540 \mathrm{~nm}$ was measured by Microplate reader (Model 3550, Bio-Rad).

\section{DNA Fragmentation Assay:}

This is done according to the method of (28). In apoptosis DNA is broken down into fragments ranging from 20-200 base pairs. Separation of both fragmented and total DNA was performed on lymphocytes lysed with Cell lysing buffer $(0.1 \%$ Triton X-100, $5 \mathrm{mM}$ Tris$\mathrm{HCl}, \mathrm{pH} \mathrm{8,} 20 \mathrm{mM}$ EDTA). Such fragments were gradiently separated from the intact DNA

using polyethelene glycol (5\% in Ethyl ether) were then quantified spectrophotometrically using Hoechst $33258(0.2 \mu \mathrm{g} / \mathrm{ml})$ as a chromophore

\section{Results:}




\section{Blood Antioxidant Enzymes:}

Table 1: Mean and SD of antioxidant enzymes before and after 24 hours post He:Ne laser irradiation of cyanotic and acyanotic patients compared to controls

\begin{tabular}{|c|l|c|c|c|}
\hline & Enzyme & $\begin{array}{l}\text { Acyanotic } \\
\text { Patients }\end{array}$ & $\begin{array}{l}\text { Cyanotic } \\
\text { patients }\end{array}$ & Controls \\
\hline \multirow{3}{*}{ Initial Levels } & SOD Units/ml & $\mathbf{5 . 7} \pm \mathbf{1 . 6}$ & $\mathbf{4 . 5} \pm \mathbf{1 . 5}$ & $\mathbf{7 . 7} \pm \mathbf{1 . 6}$ \\
\cline { 2 - 5 } & GPx Units/ml & $\mathbf{2 3 1 . 4} \pm \mathbf{6 5 . 5}$ & $\mathbf{2 5 2 . 2} \pm \mathbf{4 6}$ & $\mathbf{2 5 6} \pm \mathbf{8 4}$ \\
\cline { 2 - 5 } & CAT Units/ml & $\mathbf{4 . 4} \pm \mathbf{1}$ & $\mathbf{4 . 3} \pm \mathbf{0 . 9}$ & $\mathbf{7 . 8} \pm \mathbf{1 . 6}$ \\
\hline \multirow{3}{*}{$\begin{array}{c}\mathbf{2 4} \\
\text { hrs without laser } \\
\text { irradiation }\end{array}$} & SOD Units/m & $\mathbf{4 . 2} \pm \mathbf{1 . 3}$ & $\mathbf{3 . 8} \pm \mathbf{1}$ & $\mathbf{6 . 5} \pm \mathbf{1 . 5}$ \\
\cline { 2 - 5 } & GPx Units/ml & $\mathbf{2 5 0} \pm \mathbf{4 5 . 4}$ & $\mathbf{2 5 1 . 7} \pm \mathbf{8 2 . 6}$ & $\mathbf{2 1 6} \pm \mathbf{6 4}$ \\
\cline { 2 - 5 } $\begin{array}{c}\mathbf{2 4} \\
\text { hrs post } \\
\text { laser irradiation }\end{array}$ & CAT Units/ml & $\mathbf{4 . 2} \pm \mathbf{1 . 2}$ & $\mathbf{3 . 5} \pm \mathbf{1 . 8}$ & $\mathbf{6 . 4} \pm \mathbf{0 . 9}$ \\
\cline { 2 - 5 } & SOD Units/m & $\mathbf{2 . 6} \pm \mathbf{0 . 4}$ & $\mathbf{3 . 4} \pm \mathbf{0 . 8}$ & $\mathbf{7 . 5} \pm \mathbf{2 . 5}$ \\
\cline { 2 - 5 } & GPx Units/ml & $\mathbf{2 3 5 . 5} \pm \mathbf{2 6 . 3}$ & $\mathbf{2 2 5} \pm \mathbf{5 2 . 4}$ & $\mathbf{2 9 5} \pm \mathbf{5 2 . 4}$ \\
\hline \multirow{2}{*}{ CAT Units/ml } & $\mathbf{6 . 4} \pm \mathbf{1 . 3}$ & $\mathbf{7 . 3} \pm \mathbf{1 . 1}$ & $\mathbf{7 . 5} \pm \mathbf{0 . 4}$ \\
\hline
\end{tabular}

Table I. Shows that there mean \pm SD of blood SOD, CAT and GPx enzymes of cyanotic and acyanotic congenital heart disease children cases are non-significantly less when compared to controls. There was no significant difference in blood mean \pm SD of blood SOD, CAT and GPx enzymes between the two groups of congenital heat disease patients in the study investigated. However, 24 hours post cardiac catheterization, blood mean $\pm \mathrm{SD}$ of blood SOD, CAT and GPx enzymes significantly decreased in both cyanotic and acyanotic cases compared to controls and to their own level during catheterization. 24 hours post cardiac catheterization. Laser irradiation induced a non-significant in increase both acyanotic and cyanotic patients 24 hours post irradiation, while blood from control cases showed a significant increase in Catalase in vitro 24 hours post laser irradiation.

Apoptosis in Circulating Lymphocytes

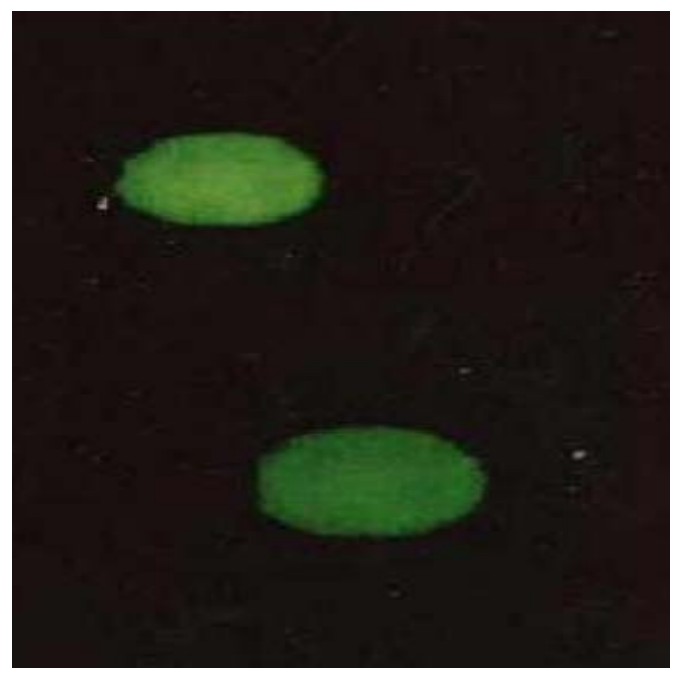

Fig 1. Viability in circulating lymphocytes of lymphocytes a control case

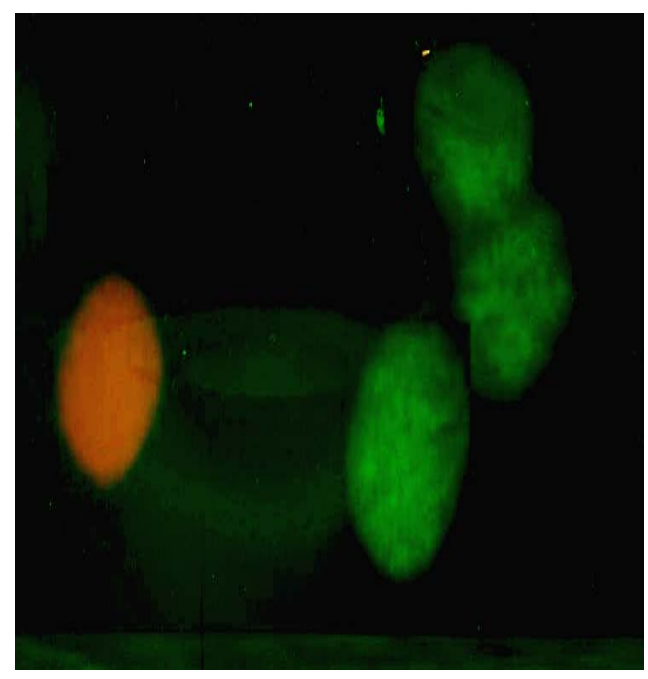

Fig.2 Apoptosis in circulating of cyanoticongenital heart disease 


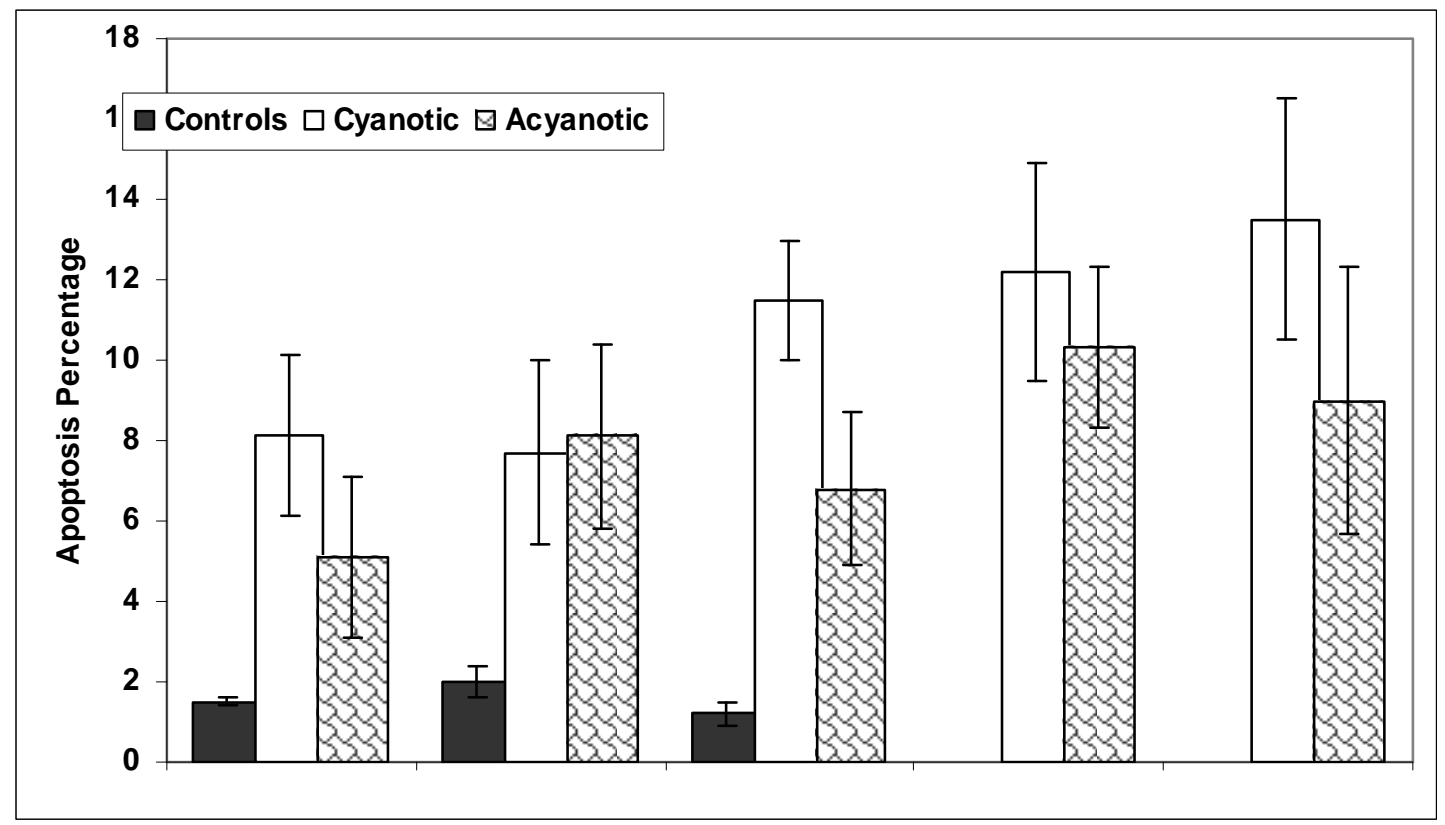

Fig. 3 Apoptosis percentage of circulating blood lymphocytes of Cyanotic, Acyanotic Congenital heart disease patients before and 24 hours with and without laser irradiation

Shows that there was significant increase in mean \pm SD apoptotic percentage of circulating lymphocytes of cyanotic and acyanotic patients before compared to controls. However apoptotic percentage of circulating lymphocytes when measured 24 hours post catheterization showed a significant increase in blood of cyanotic patients $(9.5 \pm 1$ vs. $8.1 \pm 1.1, \mathrm{t}=2.7$, $\mathrm{p}<0.05)$ compared to their level 24 hours before, while in blood of acyanotic patients during catheterization $(6.7 \pm 3.4$ vs. $7.7 \pm 0.7, \mathrm{t}=.7, \mathrm{p}>0.05)$ the increase was non-significant compared to their level 24 hours before.

\section{DNA Fragmentation:}

Fig. 3 shows that there was significant increase in mean \pm SD apoptotic percentage of DNA fragmentation of cyanotic and acyanotic patients before compared to controls. However of DNA fragmentation when measured 24 hours post catheterization showed a significant increase in blood of cyanotic patients compared to their level 24 hours before, while in blood of acyanotic patients during catheterization the increase was non-significant. compared to their level 24 hours before. 


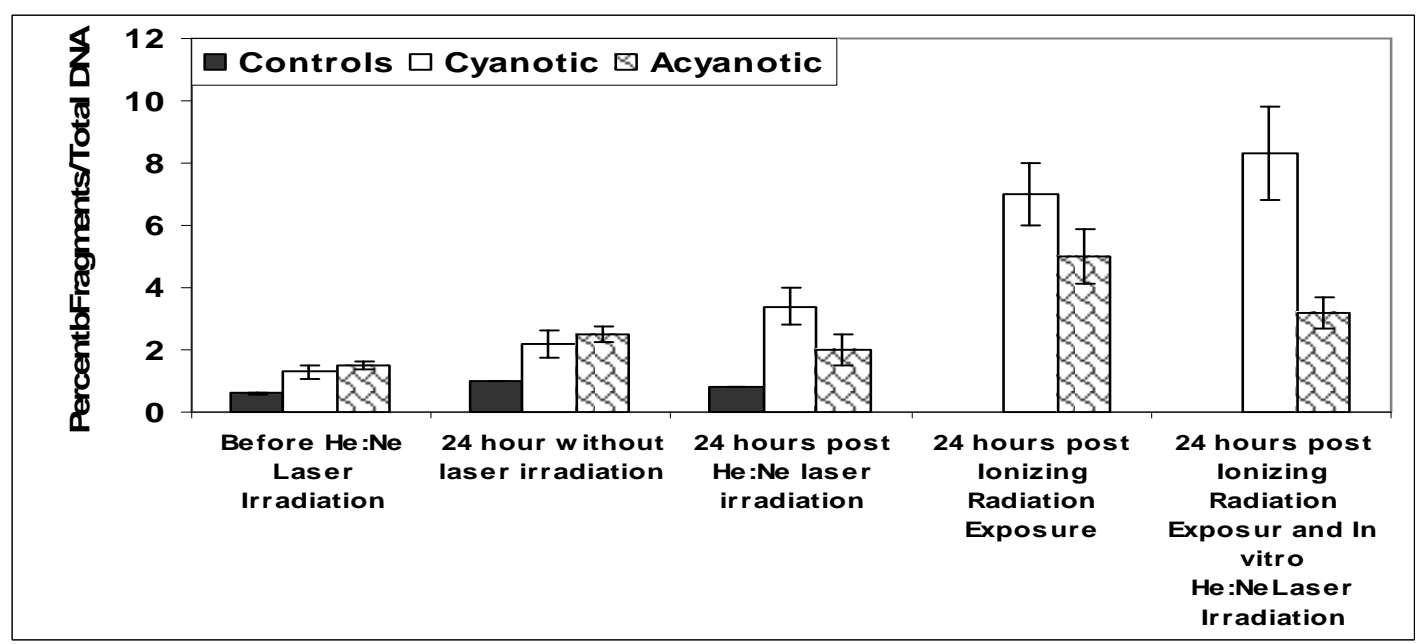

Fig. 4: Percentage of DNA fragmentation in blood of Cyanotic, Acyanotic cardiac catheterization Congenital hear disease patients before catheterization and 24 hours post cardiac catheterization with and without laser irradiation

\section{Nitrite/nitrate in plasma}

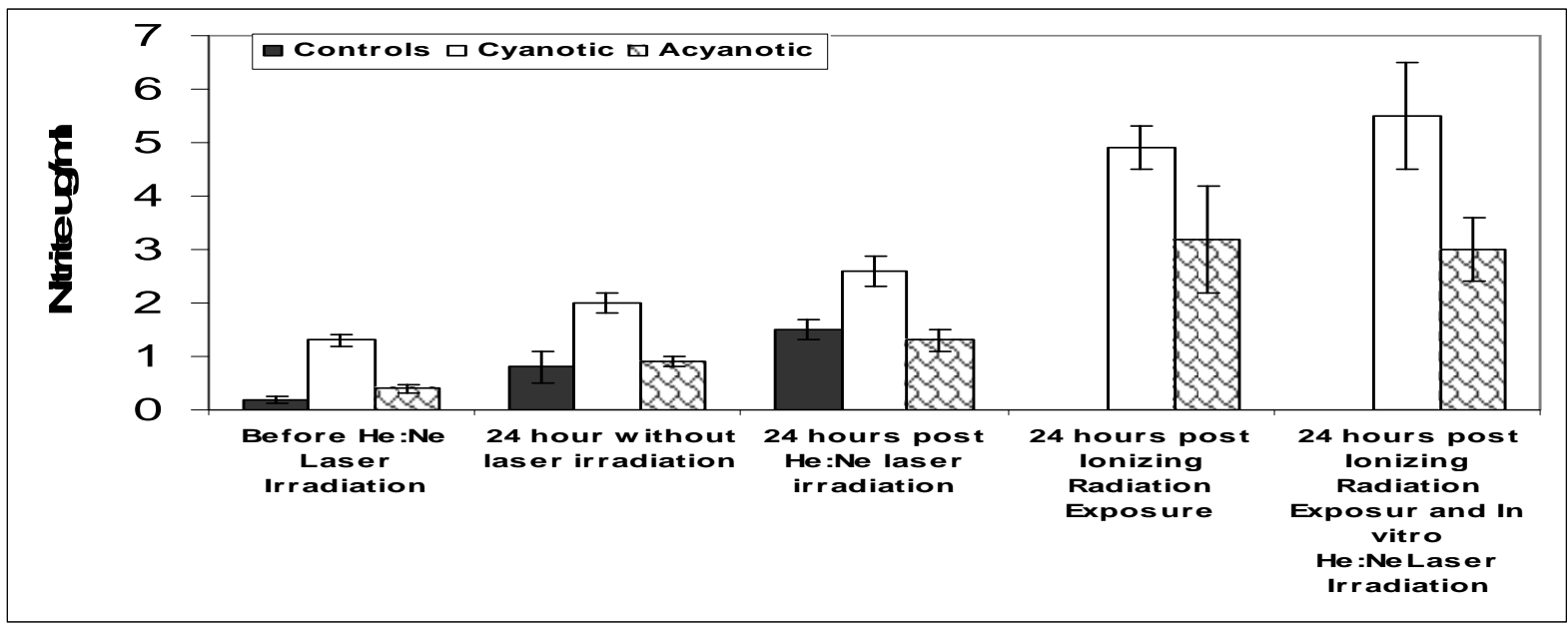

Fig. 5 Levels of nitrite/nitrate in blood of Cyanotic, Acyanotic cardiac catheterization Congenital hear disease patients before catheterization and 24 hours post cardiac catheterization with and without laser irradiation

Before catheterization and exposure to laser irradiation cyanotic patients showed the highest significant levels of nitrite/nitrate in blood followed by acyanotic when compatred to controls. There was significant increase in plasma nitrite in controls, cyanotic and a acyanotic cases 24 hours post irradiation with laser compared to their level without laser irradiation. However, cyanotic cases showed the highest significant value and were significantly higher when compared to both cyanotic and acyanotic cases.

\section{Discussion}

Both cyanotic and acyanotic congenital hear failure patients suffer from a deficit in tissue $\mathrm{O}_{2}$ delivery as a result of an inequilibrium in $\mathrm{O}_{2}$ saturation of $\mathrm{Hb}$, implicating a role for rbcs (33). This dysfunction of rbcs (34) may result from both sustained hypoxemia and NO/redox

disequilibrium within the rbc. Hypoxemia has been shown to favor retention of NO on the hemes of $\mathrm{T}$ structured (deoxygenated) $\mathrm{Hb}$, (33).Concurrently, the oxidase activity of $\mathrm{Hb}$ 
would be increased by chronic venous and tissue hypoxia $(35,36)$ leading to consequent production of ROS by hypoxic rbcs. Altered cellular production of ROS and/or reactive nitrogen species (RNS) is a ubiquitous feature of human disease. It has been widely assumed that chemical (oxidative and nitrosative) injury ROS and RNS directly damage lipids, DNA, and proteins $(21,23)$. Thus the significant increase in lipid peroxidation and DNA damage among both cyanotic and cyanotic patients compared to controls is a result of hypoxia induced generation of ROS and RNS. This increase in lipid peroxidation and DNA damage was significantly decrease upon exposure to $3 \mathrm{~J} / \mathrm{cm}^{2} \mathrm{He}: \mathrm{Ne}$ laser among acyanotic patients and significantly increased in cyanotic patients

Oxygen homeostasis represents an important organizing principle for human development and physiology. Oxygen supply, transport, and utilization process is essential for normal cellular function fueled mainly by ATP generated through oxidative phosphorylation. The essential requirement for oxidative phosphorylation to generate ATP is balanced by the risk of oxidative damage to cellular lipids, nucleic acids, and proteins (15). This delicate balance is disrupted in heart disease, cerebrovascular disease, and chronic obstructive pulmonary disease, where the since the lack of oxygen diminishes the oxidative phosphorylation pathway in mitochondria (17).

In general, as oxygen levels decrease adaptive responses to hypoxia in mammals can serve to (1) stimulate the production of red blood cells through erythropoiesis and such cells become potential sources for ATP production during hypoxia (37), (2) enhance angiogenesis by varying expression and regulation of angiogenesis-related factors and receptors (38), (3) and/or adapt cells to generate ATP mainly from anaerobic glycolysis in the cytoplasm (39).. Adaptation has its greater reliance on glycolysis by increasing glucose transporter and glycolytic enzyme expression is regulated by Hypoxia-inducible factor 1 (HIF-1). HIF-1 activates erythropoietin gene transcription and enhance the expression of RNAs encoding the glycolytic enzymes aldolase A (ALDA), phosphoglycerate kinase 1 (PGK1), and pyruvate kinase $M$ (40). This abnormal production of ATP will affect oxygen sensors of the mitochondria, which becomes a potential source of reactive oxygen free radicals (ROS) generation (41). (ROS) (40)

Thus hypoxia is a potential cause for the generation of reactive oxygen species $(41,15)$. The ROS that might be formed include superoxide, hydrogen peroxide, nitric oxide, and hydroxyl radicals. ROS are reactive chemical species that differ from other compounds in that they have unpaired electrons in their outer orbitals. They are highly reactive molecules that avidly attack biomolecules (43) including cellular DNA, proteins and lipids inducing DNA-damage (44), protein carbonyls and lipid peroxidation (44).

Systemic hypoxia is a common pathophysiological condition observed in children born with congenital heart malformation. In such conditions, the oxygen supply, transport, and utilization process is disrupted, resulting in tissue oxygen deficiency and impairment of the normal cellular function fueled mainly by ATP generated through oxidative phosphorylation. It is expected that any reduction of tissue oxygenation in vivo and in vitro would therefore provide a mechanistic stimulus for a graded and adaptive response (15). In cyanotic and acyanotic congenital heart disease, oxygen delivery is impaired either by reduced pulmonary perfusion or by limited entry of oxygenated blood into the systemic circulation and pulmonary hypertension (45), experimentally showed that heart failure is associated with an increased in oxidative stress, where decrease in oxygen tension changes ventilatory response (46).

Results of the present study showed that there was a significant increase in mean \pm SD of plasma MDA of cyanotic cases before surgery, cyanotic cases before catheterization, 
acyanotic cases before catheterization and acyanotic cases before surgery compared to controls. This finding confirms previous studies that indicated ischaemic heart diseases are associated with increased plsma levels of lipid peroxides (47). It is also consistent with that of Demikhova et al., (1995) (48), who showed that respiratory failure activates lipid peroxidation and confirms previous findings that showed that cyanotic patients had decreased tissue oxygen tension, intensified lipid peroxidation, an altered lipid profile in the red blood cell membranes compared to healthy children (49) .

In this study there was no significant differences in plasma MDA between the four groups including of cyanotic cases before surgery, cyanotic cases before catheterization, acyanotic cases before catheterization and acyanotic cases before surgery, which is not consistent with that of Komai et al., (1994) (50), who found increased levels of plasma MDA in cyanotic patients compared to acyanotic patients.

Lipid peroxidation induced by hypoxia has been shown by Bagenholm et al., (1997) (51). It is suggested that the production of nitric oxide is high in animals with hypoxic pulmonary hypertension and the serum concentration of nitrotyrosine (radical product of nitric oxide and superoxide interaction) is also increased due to chronic hypoxia (52).

Plasma MDA when measured 24 hours post catheterization showed a significant increase in acyanotic cases during catheterization compared to their level in vitro 24 hours later $(6.4 \pm$ 1.3 vs. $7.7 \pm 0.7, \mathrm{t}=3.5, \mathrm{p}<0.001)$. Similarly were the cyanotic cases during catheterization compared to their level in vitro 24 hours later $(5.4 \pm 1.2$ vs. $7.3 \pm 1.1, \mathrm{t}=2.8, \mathrm{p}<0.05)$. indicates a late response which can be attributed to the fact that endothelial cells lining up blood capillaries have numerous oxidants enzymes systems including: NADPH oxidase (53) xanthine oxidase (55) and nitric oxide synthase (54) generate reactive oxygen species and nitrogen reactive oxygen species. In addition, neutrophils and other inflammatory cells generate and release reactive oxygen species via an NADPH-oxidase-dependent mechanism that is mediated by membrane receptor activation of protein kinase $\mathrm{C}$ and phospholipase (55). One of the major functions of these free radicals is immunological host defense, where they are generated by macrophages and neutrophils and play critical role as bactericidal, antiviral and anti-tumor agent (56). Endothelial nitric oxide present in endothelial cells is expressed in cells 6 hours post exposure (54) and cytokines and inflammatory mediators are not stored in a cell, they have to be transcribed, expressed and synthesized. And thus a late response is expected explaining the increase in lipid peroixidation observed 24 hours post catheterization in vitro. The fact that an inflammatory response is associated with cateterization procedure has been previously shown in several other studies $(57,58)$.

It is also evident that laser irradiation induced a significant increase in plasma MDA of cyanotic blood, while in controls and acyanotic cases the increase was non significant in vitro 24 hours post catheterization,. This finding is consistent with that of others that showed that lipid peroxidation measured in terms of thiobarbituric acid-reactive substances (TBARS) were demonstrated in a 10-minute period in mouse irradiated epidermal tissue compared to unirradiated skin control health animals animals. (59). The reason for the increase in MDA in cyantic-irradiated blood is due to the fact that cyanotic cases have ability to generate higher levels of nitric oxide compared to acyanotic cases. It is revealed that inducible nitric oxide synthase activity and expression are increased in cyanotic children compared to acyanotic children (59) and He:Ne laser irradiation has been shown to significantly induce the activation and expression of iNOS mRNA have been recently demonstrated in human buffy coat neutrophils irradiated with He:Ne laser at doses 1, 2.5 and $5 \mathrm{~J} / \mathrm{cm}^{2}(60)$. In case of controls the efficient antioxidant mechanism could explain the non-significant increase in MDA and a redox effect of He:Ne laser irradiation on cells explains the non-significant increase in lipid peroxidation observed in the acyanotic irradiated blood (61). Stimulation of a redox effect 
triggers cellular adaptation and the induction of defense mechanisms and induce phase transition of a cell from a quiescent state to a proliferative, apoptotic, or necrotic state against oxidative stress elicits cellular toxicity implicating various targets such as DNA, RNA, proteins, and lipids, it (62).

Apoptosis or programmed cell death is induced via a free radical mechanism $(\mathbf{B r 4 3}, 6 \mathbf{6 3 )}$ which is characterized by certain morphological features such as loss of membrane asymmetry and attachment, condensation of the cytoplasm and nucleus, and intranucleosomal cleavage of DNA. The dying cells fragmenting into apoptotic bodies, which are rapidly eliminated by phagocytic cells without eliciting significant inflammatory damage (64). Apoptosis is considered as one of the antioxidant mechanisms for the elimination of oxidative damage to cellular DNA (55). Thus the significant increase in mean \pm SD of apoptotic percentage in circulating lymphocytes of cyanotic patients before surgery; cyanotic patients during catheterization, acyanotic during catheterization and acyanotic patients before surgery compared to controls could be considered as an adaptive response to hypoxia induced free radical generation, where an increase in the elimination of genetically damaged cells by apoptosis represent an adaptive response mechanism (65).

Also the significant increase in apoptotic percentage of observed in cyanotic and acyanotic bloods in vitro 24 hours post cardiac catheterization procedure and incubation for 24 hours compared to of cyanotic cases before surgery, cyanotic cases before catheterization, acyanotic cases before catheterization and acyanotic cases before surgery and to controls could either be due to the inflammatory response induced during the catheterization procedure (66) which induces substantial amounts of ROS.

The significant increase in mean \pm SD of DNA fragmentation and apoptotic percentage in circulating lymphocytes of cyanotic patients before surgery, cyanotic during catheterization, acyanotic during catheterization and acyanotic cases during surgery compared to controls is consistent with the fact that under hypoxia, cells either adapt themselves or are irreversibly injured and die (66). It is believed that reactive oxygen species (ROS) activates a cell death mediator termed caspase-9, which upon activation induces permeability transition (PT)independent cytochrome $\mathrm{c}$ release from the mitochondria (67). It has been previously demonstrated that ATP, generated through glycolysis, is a critical determinant of the form of cell death in hypoxic myocytes, independently of cellular acidification. Our data suggest that necrosis and apoptosis represent different outcomes of the same pathway. In the absence of ATP, necrosis prevails. However, the presence of ATP favors and promotes apoptosis (68).

Laser irradiation induced a significant increase in the apoptotic percentage and DNA fragmentation of circulating lymphoicytes of cyanotic blood, while in controls and acyanotic cases the increase was non significant in vitro 24 hours post catheterization, This finding is consistent with that of others that showed that low doses of He:Ne laser promotes the cell cycle entry in lymphocytes (69) and satellite cells around fibers and also has an inhibitory effect of on cell apoptosis, which was accompanied with increasing Bcl-2 and decreasing BAX expression in both these fibers and myogenic cultured cells (70).

Serum and plasma DNA fragments has been detected after ischemic or traumatic injury, (71, 72). Chronic venous leg ulcers are characterized by excessive or prolonged inflammation, which is accompanied by an increase in reactive oxygen species released from polymorphonuclear leukocytes and proteinases, together with increased connective tissue degradation and lipid peroxidation which further contribute to the prooxidant hostile microenvironment (73). Eventually during the chronic inflammatory phase necrotic DNA are present due to the presence of lysing and proteolytic enzymes (74). Also the presence of ROS and NO contributes to DNA-fragmentation pattern (73). To our knowledge this is the first time DNA fragmentation or apptosis has been assayed in circulating blood of cyanotic or cyanotic patients. 
In this present study antioxidant enzymes showed no significant differences in their levels, although they were lower in their levels compared to controls. This finding is consistent with that of Rokicki et al., 2003 (76), who showed that the activities of superoxide dismutase and catalase in infants with congenital heart were not significantly different from the respective values recorded in healthy controls. In this present study acyanotic patients showed significantly lower levels of GPX, while in their study the activity of glutathione peroxidase in whole blood was the lowest in infants with cyanotic heart defect. Thus inconsistency my be just due to a familial inheritance in the ability for the induction and expression in the activity of antioxidant enzymes. There is a recorded genetic variability in antioxidant enzymes, which are encoded by numerous genes in mammalian systems, Antioxidant enzymes responsive to oxidants, although a systematic mechanism for gene regulation by oxidative stress has not been elucidated. However it is believed to be under the regulation of the hypoxia inducible factor predominant enzymatic mechanisms that regulate intracellular ROS levels are mediated by superoxide dismutase, catalase and glutathione peroxidase. The tetrameric catalase converts $\mathrm{H}_{2} \mathrm{O}_{2}$ to $\mathrm{H}_{2} \mathrm{O}$ and $\mathrm{O}_{2}$ in peroxisomes $(77,78)$. Glutathione peroxidase converts $\mathrm{H}_{2} \mathrm{O}_{2}$ to $\mathrm{H}_{2} \mathrm{O}$ in a reaction that oxidizes GSH to its disulfide form (GSSG). In turn, GSH is regenerated from GSSG by glutathione reductase. Regulation of $\mathrm{H}_{2} \mathrm{O}_{2}$ by the glutathione redox cycle is mediated in the cytosol and mitochondria. In this present study with the exception of peroxidase in cyanotic patients during surgery there has been a significant decrease in antioxidant enzymes observed in cyanotic and acyanotic bloods in vitro 24 hours post cardiac catheterization procedure and incubation for 24 hours compared to of cyanotic cases before surgery, cyanotic cases before catheterization, acyanotic cases before catheterization and acyanotic cases before surgery and to controls. This decrease in antioxidant enzymes is most probably due to the increased tendency to eliminate reactive oxygen species and consequently induces an increase in its consumption.

In controls laser increased the level of catalase enzyme 24 hours post laser irradiation compared to its level before irradiation. The increase in level of serum CAT is compatible with in vitro results (79), which showed that low intensity laser (Argon-dye $660 \mathrm{~nm} 16.8$ $\mathrm{J} / \mathrm{cm}^{2}$ ) irradiation of isolated cardiomyocytes exhibited higher CAT activity when compared to controls. In vivo irradiation of hairless mice epidermises caused a significant increase in CAT levels (Kim et al.,, 2000). It was suggested that laser therapy efficacy in chronic wounds and ulcers can be attributed to the activation of CAT in tissue fluids (80). Also He:Ne laser has been shown to cause photoactivation and structural modifications of catalase enzyme that positively correlated with its functional properties in cell free system (81)

Cyanotic and acyanotic heart congenital heart diseases have different reaction towards laser effect from that of controls. Twenty-four hours post cardiac catheterization, blood catalase enzyme decreased non- significantly in both cyanotic and acyanotic cases compared to controls and to their own level during catheterization. Laser irradiation induced a nonsignificant decrease in both acyanotic patients 24 hours post irrradiation, The reason for this indifference is that increased level of oxidative stress in those patients was beyond catalase capacity to eliminate and formed $\mathrm{H} 2 \mathrm{O} 2$ is beyond the endogenous catalase capacity.

Twenty-four hours post cardiac catheterization, blood superoxide dismutase enzyme significantly decreased in controls and laser significantly increased its level. This finding is consistent with previous findings, which showed that the activity of SOD has been shown, previously, to increase insignificaly in the skin of animals irradiated with He:Ne laser, at doses above $4 \mathrm{~J} / \mathrm{cm}^{2}(82)$ and below $3 \mathrm{~J} / \mathrm{cm}^{2}$ (Kim et al., 2000). 
Meanwhile, 24 hours post cardiac catheterization, blood superoxide dismutase enzyme significantly decreased in both cyanotic and acyanotic cases compared to controls and to their own level during catheterization. Laser significantly decreased blood superoxide dismutase enzyme in both the cyanotic and the acyanotic patients. This also could be attributed to the fact that that increased level of oxidative stress in those patients was beyond endogenous SOD capacity to eliminate and formed superoxide radicals.

In conclusion congenital heart disease as results in oxidative stress that characterized by increase in apoptotic percentage, DNA fragmentation and lipid per oxidation compared to healthy controls. This oxidative stress is compensated by antioxidant enzymes, which decrease as a result of their consumption during cardiac catheterization procedure. Exposure to low doses of He:Ne laser ameliorates the damaging effects in acyanotic patients but augments the damaging effects in cyanotic patients

\section{References}

1. Conlan, M. J., Rapley, J. W. and Cobb, C. M. (1996). Biostimulation of wound healing by low-energy laser irradiation. A review. J. Clin. Periodontol. 23,492 -496.

2. Weiss, N. and Oron, U. (1992). Enhancement of muscle regeneration in the rat gastrocnemius muscle by low energy laser irradiation. Anat. Embryol. 186,497 -503

3. Bibikova, A. and Oron, U. (1993). Promotion of muscle regeneration in the toad (Bufo virdis) gastrocnemius muscle by low-energy laser irradiation. Anal. Rec. 235,374 -380.

4. Bibikova, A., Belkin, A. and Oron, U. (1994). Enhancement of angiogenesis in regenerating gastrocnemius muscle of the toad (Bufo virdis) by low energy laser irradiation Anat. Embryol. 190,597 -602

5. Gatsura SV, Gladkikh SP, Titov MN.Effect of low-energy laser irradiation on the area of experimental myocardial infarction, lipid peroxidation, and hemoglobin affinity for oxygen. Bull Exp Biol Med. 2004 Apr;137(4):355-7.

6.Vasil'ev AP, Strel'tsova NN, Senatorov IuN.Laser irradiation in the treatment of ischemic heart disease, Vopr Kurortol Fizioter Lech Fiz Kult. 2001, (6):10-3.

7.H. Huang, A. Qureshi, J. Biundo, Sports and other soft tissue injuries, tendinitis, bursitis, and occupation-related syndromes. Curr Opin Rheumatol. 12 (2000) 150-4.

8.Vin'cova GA; Ionin AP and Ionin GI, (1999): The treatment of post Traumatic uveitis with low-intensity laser radiation. Vestn Oftalmol, 115: 209-1.

9.Zhu Q, Yu W, Yang X, et al. Photo-irradiation improved functional preservation of the isolated rat heart. Lasers Surg Med. 1997;20:332-339.

10. Oron, U., Yaakobi, T., Oron, A., Mordechovitz, D., Shofti, R., Hayam, G., Dror, U., Gepstein, L., Wolf, T., Haudenschild, C. and Ben Haim, S. (2001). Low energy laser irradiation reduces formation of scar tissue following myocardial infraction in dogs. Circulation 103,296 -301.

11. Ference C., Loffredo C. , Correa-Villasenor A., and Wilson P. : The Baltimore Washington infant study. Futura Armonk, NY 1997 :1981-1989.

12. Trittenwein G, Furst G, Golej J, Frenzel K, Burda G, Hermon M, Marx M, Wollenek G, Pollak A.: Preoperative ECMO in congenital cyanotic heart disease using the AREC system. Ann Thorac Surg. 1997 May; 63(5):1298-302.

13. Chandel NS, Maltepe E, Goldwasser E, Mathieu CE, Simon MC, Schumacker PT: Mitochondrial reactive oxygen species trigger hypoxia-induced transcription. Proc Natl Acad Sci U S A. 1998 Sep 29; 95(20):11715-20.

14. SJ. Schuster, EV. Badiavas, P. Costa-Giomi, R. Weinmann, AJ. Erslev and J. Caro: Stimulation of erythropoietin gene transcription during hypoxia and cobalt exposure. Blood; Volume 73, Issue 1, pp.1989: 13-16. 
15. Semenza GL. HIF-1 and mechanisms of hypoxia sensing. Curr Opin Cell Biol. 2001 Apr;13(2):167-71.

16. GL. Semenza , PH. Roth , HM. Fang and GL. Wang: Transcriptional regulation of genes encoding glycolytic enzymes by hypoxia-inducible factor 1. J. Biol. Chem., Vol. 269 1994, Issue 38, 23757-23763.

17. Greenlee, R.T. 2000. Cancer statistics. CA Cancer J. Clinicians 50: 7-33

18. Haywood, GA, Tsao PS, von der Leyen HE, Mann MJ, Keeling PJ, Trindade PT, Lewis NP, Byrne CD, Rickenbacher PR, Bishopric NH, Cooke JP, McKenna WJ, and Fowler MB. Expression of inducible nitric oxide synthase in human heart failure. Circulation 93: 10871094, 1996

19. Younes M, Strubelt O.: The involvement of reactive oxygen species in hypoxic injury to rat liver. Res Commun Chem Pathol Pharmacol. 1988 Mar ; 59 (3) : 369-81.

20. Semenza GL. : HIF-1 and mechanisms of hypoxia sensing. Curr Opin Cell Biol. 2001 Apr ; $13(2): 167-71$

21. Weisman H. and Halliwell B.: Damage to DNA by reactive nitrogen and oxygen species: role in inflammatory disease and progression to cancer. Biochem, J., 1996; 313: 17 - 29

22. Briehl M., Baker L., M. Siemankowski,, and J. Morreale: Modulation of antioxidant defenses during apoptosis. Oncol. Res., 1997; 9: 281-285.

23. J.M.C Gutteridge: lipid peroxidation and antioxidants as biomarkers of tissues damage . Clin. Chem., 1995; 41 (12) : 1819-1828.

24. uuuuu

25. Plagia DE, Valentine WN. Studies on the quantitative and qualitative characterization of erythrocyte glutathione peroxidase. J Lab Clin Med 1967; 70:158-169.

26. Suttle, N. and McMurray, C., Res. In Vet. Sc. 1983; 35: 1569 - 1575.

27. Johansson LH, Hakan Borg LA. A spectrophotometric method for determination of catalase activity in small tissue samples. Anal Biochem 1988; 174:331-336.

28. Ioannou, Y. and Chen F.: Quantification of DNA fragmentation in apoptosis. Nucleic Acid Research, 1996, 24(5): 992-883

29. El-Ahmady O, El-Salahy E, Mahmoud M, Wahab MA, Eissa S, and Khalifa A.: Multivariate analysis of bcl-2, apoptosis, P53 and HER-2/neu in breast cancer: a shortterm follow-up. Anticancer Res. 2002; 22 (4) : 2493-9.

30. Misko, T.P., Schilling, R.J., Salvemini, D. et al.: A fluorometric assay for the measurement of nitrite in biological samples. Anal. Biochem., 1993; 214, 11-16.

31. Singel, D.J., and Stamler, J.S. 2005. Chemical physiology of blood flow regulation by red blood cells: The role of nitric oxide and S-nitrosohemoglobin. Annu. Rev. Physiol. 67:99-145.

32. Datta, B. et al. 2004. Red blood cell nitric oxide as an endocrine vasoregulator - A potential role in congestive heart failure. Circulation. 109:1339-1342.

33. Gow, A.J., and Stamler, J.S. 1998. Reactions between nitric oxide and haemoglobin under physiological conditions. Nature. 391:169-173.

34. Balagopalakrishna, C., Manoharan, P.T., Abugo, O.O., and Rifkind, J.M. 1996. Production of superoxide from hemoglobin-bound oxygen under hypoxic conditions. Biochemistry. 35:6393-6398. [

35. S. Goldstone, J. Fragonas, T. Jeitner, N. Hunt, Transcription factors as targets for oxidative signaling during lymphocyte activation, Biochem. Biophys. Acta 1263 (1995) 114-122.

36. H. Lander, P. Sehajpal, D. Levine, A. Novogrodsky, Activation of human peripheral blood mononuclear cells with nitric oxide-generating compounds, J. of Immunol. 150 (1993) 1509-1516

37. Sprague RS, Stephenson AH, Ellsworth ML, Keller C, Lonigro AJ.Impaired release of ATP from red blood cells of humans with primary pulmonary hypertension. Exp Biol Med (Maywood). 2001 May;226(5):434-9. 
38. Tscheudschilsuren G, Aust G, Nieber K, Schilling N, Spanel-Borowski K.Microvascular endothelial cells differ in basal and hypoxia-regulated expression of angiogenic factors and their receptors. Microvasc Res. 2002 May;63(3):243-51.

39. Eble, A.S.,S.R. Thorpe, andJ.W. Baynes(1983)Nonenzymatic glucosylation and glucosedependent cross-linking of protein. J. Biol. Chem.258:9406-9412

40. GL Semenza, PH Roth, HM Fang and GL Wang Transcriptional regulation of genes encoding glycolytic enzymes by hypoxia-inducible factor 1 J. Biol. Chem., Vol. 269, Issue 38, 23757-23763, 09, 1994 